Zarouali, B., Poels, K., Ponnet, K., Walrave, M. (2018). “Everything under control?": Privacy control salience influences both critical processing and perceived persuasiveness of targeted advertising among adolescents. Cyberpsychology: Journal of Psychosocial Research on Cyberspace, 12(1), article 5. doi: https://doi.org/10.5817/CP2018-1-5

\title{
"Everything under control?": Privacy control salience influences both critical processing and perceived persuasiveness of targeted advertising among adolescents
}

\author{
Brahim Zarouali ${ }^{1}$, Karolien Poels ${ }^{1}$, Koen Ponnet $^{1,2}$, \& Michel Walrave ${ }^{1}$ \\ 1 Department of Communication Studies (MIOS), University of Antwerp, Antwerp, Belgium \\ 2 Department of Communication Sciences (IMEC-MICT), Ghent University, Ghent, Belgium
}

\begin{abstract}
Given that adolescents continuously interact with the user interface of a social networking site, it might be a strategic place to address privacy-related issues. This study investigates whether and how privacy control features embedded in Facebook's user interface could serve as a cue to influence adolescents in their critical processing and perceived persuasiveness of targeted advertisements. To test this, an experimental study among 178 adolescents aged 14-16 years was conducted. Results reveal that increasing privacy control salience by means of user interface elements leads to more critical processing of targeted advertising; at the same time, when adolescents perceive a higher privacy control, they also evaluate a targeted ad as more effective, convincing and reliable (i.e., increase in perceived persuasiveness). The study further identifies two underlying mechanisms by which these effects operate: perceived control and self-efficacy. Based on these findings, theoretical contributions and practical implications are discussed to optimize advertising campaigns on social networking sites in a responsible and privacy-protective way.
\end{abstract}

Keywords: Advertising; privacy control; Facebook; critical processing; persuasion

\section{Introduction}

Over the past decade adolescents have entirely embraced social networking sites (SNSs) in their daily life. Although the social media landscape evolves at breakneck speed, Facebook still reigns as one of the most popular SNSs among teens (Ofcom, 2017; PEW Research Center, 2018). This popularity of SNSs has offered companies an important venue for their commercial agendas. More precisely, brands have the opportunity to engage in targeted news feed ads, which have been referred to as "sponsored posts". Such ads can be textual posts, videos, images, or newer formats such as carrousel and canvas ads. Importantly, these ads take the form of an ordinary (organic) post as they adopt the format and style of the SNS (Aguirre, Roggeveen, Grewal, \& Wetzels, 2016). Recent studies indicated that adolescents are not sophisticated decoders when it comes to interpreting these embedded sponsored posts as commercial attempts (Lawlor, Dunne, \& Rowley, 2016; Zarouali, Ponnet, Walrave, \& Poels, 2017). This issue has recently been the subject of heightened public and academic concerns and is mainly fueled by questions on the fairness or appropriateness of commercial actors' access to and use of adolescents' personal information for advertising purposes (van Reijmersdal, Rozendaal, Smink, Noort, \& Buijzen, 2017).

Until recently, no rules or guidelines existed for labeling these type of targeted ads on SNSs (Einstein, 2016). That changed in 2015, when the Federal Trade Commission issued guidelines calling for clear cues that indicate the presence of sponsored posts. Such cues usually refer to some kind of textual disclosure or visual label that reveal the persuasive intent of a particular message online (Boerman, Kruikemeier, \& Borgesius, 2017). They are designed to inform (young) consumers of an upcoming commercial message (i.e., trigger their awareness), and hence, 
stimulate them to activate their critical persuasion awareness (Hudders et al., 2017). In the past, there has been some research on the effectiveness of such ad cues among young consumers, but this body of literature is still in its infancy. More importantly, we argue that it is marked by an important gap.

Previous studies have almost exclusively focused on advertising cues that solely convey the commercial nature of a message (e.g., "this is advertising") (Boerman \& van Reijmersdal, 2016; Quinn \& Wood, 2004). In other words, they aimed at making the persuasive intent salient. These cues are then placed in near proximity of an advertisement to test whether this warning cue can influence young consumers' critical thinking processes and responses. However, by drawing on a reflection of Hudders et al. (2017), such cues might not be equally effective for different advertising formats. In the case of advertising on Facebook, an important element is that ads are targeted based on the personal data of users. Unless they are informed properly, the latter might be perceived as scary and inappropriate by adolescents as they might feel that their privacy has been breached by this advertising practice (Walrave, Poels, Antheunis, Van den Broeck, \& Noort, 2016; Zarouali et al., 2017). Therefore, an effective cue might not necessarily be one that simply indicates that a particular message is advertising (i.e., conveying the persuasive intent); but may rather be one that informs adolescents about the targeting process including the use of personal data and reassures them that they have -to a certain degree- control over this process (e.g., the possibility to report or hide the ad, to control the amount of personal information being used, etc.) (Tucker, 2014). By drawing attention to the control over one's online privacy, by means of making privacy control salient, this type of cue could on the one hand elicit critical processing; on the other hand, it could also result in more favorable evaluations as adolescents might appreciate the fact that brands are being transparent about targeted ads (Wei, Fischer, \& Main, 2008; Wojdynski, 2016).

Therefore, we aim to explain how increasing privacy control salience by integrating privacy features in the user interface of Facebook might serve as a trigger to orient adolescents' minds in the direction of more critical elaboration of targeted advertising. At the same time, we also shed light on how increasing privacy control salience also instigates more favorable ad responses, i.e., an increase in perceived ad persuasiveness. In this respect, two important underlying mechanisms will be identified through which these effects occur: perceived control and selfefficacy.

\section{Literature Review}

Privacy on SNSs. Recent technological advances in marketing bring with them an increased ability to serve consumers with relevant content, but at the same time, also an increased risk of invading their privacy (Shimp \& Andrews, 2013). Therefore, SNSs providers have implemented a number of features over the past few years to help users check and update their privacy settings (Vitak, 2015). A good illustration is the Privacy Checkup on Facebook, which features a little blue dinosaur representing Facebook's privacy and security mascot. This privacy feature helps users control the visibility of their personal information and posts (e.g., "friends only", "public", etc.), making it easier to determine who is seeing what (Rosenblatt, 2014). However, in this respect, it is crucial to make a distinction between controlling one's social and institutional privacy (Raynes-Goldie, 2010; Young \& Quan- Haase, 2013). The former refers to protective measures to control the extent to which other users have access to your personal information (i.e., the visibility of your information to others, such as friends, peers or parents). The latter concerns protection strategies to control what personal information is accessed and used by companies and third parties for marketing purposes. Tools such as Facebook's Privacy Checkup mainly focus on addressing individuals' concerns with regards to the visibility of their information to other people (i.e., social privacy), but do not protect against the access and use of personal information by brands and companies (i.e., institutional privacy). As asserted by Brandimarte, Acquisti, \& Loewenstein (2013), SNSs such as Facebook provide a feeling of control by allowing users to change every detail of their privacy settings, which implies what type of information can be seen by whom; but in fact, users have little control over the way this information will be used by third-parties. In other words, privacy initiatives on SNSs tend to protect the tip of the iceberg, but all the underlying 'silent listeners' (e.g., third-parties, apps, advertisers, etc.) remain largely unaffected by these control tools (Debatin, Lovejoy, Horn, \& Hughes, 2009; Stutzman, Gross, \& Acquisti, 2013).

The reason why SNSs are hesitant to give users control over their institutional privacy might be the fear that raising attention to institutional privacy could lead to more cautiousness, and thus users restricting commercial actors' access to their personal information (Bonneau \& Preibusch, 2010; Burke, Marlow, \& Lento, 2009; Houghton \& 
Joinson, 2010). Adolescents may experience a feeling of privacy intrusion because they are often un- or misinformed about who is collecting their personal information, how their data are obtained and for what purposes they are used (Nowak \& Phelps, 1995; Youn, 2009). These feelings of privacy intrusion might then lead to what has been referred to as reactance, or experiencing a loss of control and threat to autonomy and freedom of choice (Brehm, 1989). Reactance can eventually result in negative feelings and responses toward targeted advertising (Boerman et al., 2017; Zarouali et al., 2017). This logic might thus explain why SNSs, such as Facebook, rarely put their institutional privacy-enhancing tools in the spotlights, even though they are -sometimes-available. However, as will be discussed in the following sections, making institutional privacy salient on Facebook does not have to generate negative responses towards targeted advertising. In the remainder of the paper, institutional privacy will simply be referred to as privacy for the sake of brevity.

Privacy control and salience. More frequently than not, the element of control is embedded in conceptualizations of privacy over the past few decades (e.g., Altman, 1975; Margulis, 1977; Smith, Milberg, \& Burke, 1996). For instance, as formulated by Westin (1967), privacy can be perceived as "the ability of the individual to control the terms under which personal information is acquired and used" (p. 7). So whether it is control over the acquisition, disclosure or use of personal information, it is central to maintaining privacy (Houghton \& Joinson, 2010; Solove, 2005). Previous literature has shown that this specific element of privacy, i.e., the lack of control over a particular situation, is one of the predominant triggers of consumer reactance and vulnerability (Baker, Gentry, \& Rittenburg, 2005; Bleier \& Eisenbeiss, 2015; Taylor, 1979). For instance, in an advertising context, Tucker (2014) argued that control over private information is important in mitigating reactance by revealing that consumers on Facebook were twice as likely to click on a personalized ad as a result of an increase in privacy control. This result countered the general view that increasing privacy control is harmful to advertising outcomes (Goldfarb \& Tucker, 2011). In addition to being beneficial to advertising responses, the increase of privacy control might also lead to consumers paying more attention to their online privacy as they feel 'more in control' of it, which results in critical reflection and making more well-thought-out decisions with respect to privacy-related matters on SNSs (e.g., Hughes-Roberts, 2015a, 2015b; Wang, Xu, \& Grossklags, 2011; Wang, Zhang, Liu, \& Jin, 2015).

Based on this line of reasoning, we argue that making privacy control salient in a social network environment might be a promising tool to encourage adolescents to engage in critical processing about targeted advertising, and at the same time, display positive ad responses. Privacy control salience can be defined as the degree to which privacy control is prominent in a person's awareness during interaction with a SNS (Williams, Nurse, \& Creese, 2016). As argued by scholars, the phenomenon of privacy control salience and its particular role in evaluating targeted advertisements needs further investigation (Bonneau \& Preibusch, 2010; Williams et al., 2016). This will be discussed in the next sections.

Privacy control salience: A cue for adolescents. Although the idea of increasing privacy control salience on SNSS might be interesting to investigate among all users in general, we argue that gaining insights into this topic among adolescents may be of particular importance. As they spend most of their days with SNSs, it is of great relevance to arrive at an accurate observation and explanation of the role of advertising on SNSs in their daily lives. However, as shown by Zarouali et al. (2017), adolescents do not engage in critical reflection on targeted advertising, unless they are exposed to a cue that triggers their critical elaboration. Without such a cue, they might be a consumer group at risk of unwanted and undesired persuasion effects. The merit of an advertising cue lies in the fact that it can succeed in notifying adolescents that they are being subjected to a persuasive attempt (Boerman \& van Reijmersdal, 2016; Quinn \& Wood, 2004). As a result, adolescents might be more aware of these persuasive attempts, which results in the adoption of a more critical processing style to evaluate an ad (Boerman, van Reijmersdal, \& Neijens, 2014; Wei et al., 2008).

Building on the previous paragraph, we now expect that features on the user interface of Facebook that convey privacy control might also act as a cue, and thus, be an interesting tool to increase critical thinking about targeted advertising among adolescents. Although it has been argued that adolescents engage in rather reckless privacy behavior and disclose a considerable amount of personal information (Barnes, 2006; Trepte \& Reinecke, 2011), others have nuanced this view by revealing that adolescents usually wish to be in control of how they manage this disclosure (Christofides, Muise, \& Desmarais, 2010; Livingstone, 2006, 2008). More precisely, control over personal information becomes increasingly integral in the privacy conceptions of children as they grow up, and even becomes a dominant point of attention by early adolescence (Hawk, Hale, Raaijmakers, \& Meeus, 2008; Wolfe \& 
Laufer, 1974). For adolescents, it is key to have control over who knows what about them, and for what purposes (Livingstone, 2006, 2008). Therefore, we expect that explicitly exposing adolescents to a clear feature in which privacy control is made salient might serve as a cue to trigger them to be aware of data collection practice involved with this form of advertising, which should activate their critical advertising processing. In sum, we suggest:

H1: As privacy control salience (low - moderate - high) induced by features on Facebook increases, it will lead to more critical processing of targeted advertising among adolescents.

In addition, we argue that an increased privacy control salience might not only lead to more critical reflection, but it might also trigger more favorable ad responses at the same time. Although research shows that a transparent cue usually triggers consumers' persuasion resistance, which generally leads to negative evaluations of advertisements (for a detailed overview, see Boerman \& van Reijmersdal, 2016), there are also some studies pointing toward the opposite direction (e.g., Eagly, Wood, \& Chaiken, 1978; Wei et al., 2008). As asserted by Wei et al. (2008), explicit disclosure of covert marketing by a brand can also result in more favorable evaluations as consumers also appreciate the fact that brands disclose the fact that their message is intended to persuade (i.e., a brand being transparent). Put simply, consumers might give more positive evaluations for greater levels of transparency in a cluttered online advertising landscape (Wojdynski, 2016). In the present study, we expect that a privacy control feature might also trigger such an effect. In the literature, consumer control has been revealed to be an initiator and driver of customer satisfaction in an online context (Chan, Barnes, \& Fukukawa, 2016). As already addressed, Tucker (2014) showed that privacy control reassures consumers on SNSs that they have a certain amount of explicit control over their customer data, which then leads to more positive responses toward personalized advertising (higher click-through-rate). On their turn, Morris, Choi and Ju (2016) found that control over targeted advertising on SNSs enhances consumer feelings of credibility and reduces intrusion. Based on this empirical evidence, we expect privacy control salience to increase the perceived persuasiveness of targeted advertising. Hence, we suggest the following hypothesis:

H2: As privacy control salience (low - moderate - high) induced by features on Facebook increases, it will lead to a higher perceived persuasiveness of targeted advertising among adolescents.

Mediating role of perceived control and self-efficacy. We further propose two important psychological mechanisms underlying these proposed effects: perceived control and self-efficacy. For the purpose of clarity, it is important to note that both are conceptually different: perceived control refers to an individual's view or perception of control within a given situation, whereas self-efficacy refers to confidence in one's own ability to carry out such control in practice (Ajzen, 2002; Armitage \& Conner, 1999). We will now enter into more detail about these two mediators.

Perceived control. Perceived control can be defined as the degree to which an individual views an event as within their control (Raines, Oglesby, Unruh, Capron, \& Schmidt, 2014). In this study, it refers to whether consumers feel they have control over managing their privacy settings on a SNS. In the literature, perceived control has been identified as an important attitudinal variable that helps explain consumer behavior in an online environment (Koufaris, Kambil, \& Labarbera, 2001). However, theorists pointed out the rather ambiguous and unclear role of perceived control in a privacy context (e.g., Margulis, 2003; Solove, 2002). Some studies provided more clarity on the nature of this variable by showing that perceived control exercised a crucial mediating role in mitigating privacy concerns (Xu, 2007; Xu, Teo, Tan, \& Agarwal, 2012). This line of reasoning might be particularly interesting to test among an adolescent sample. In the literature, adolescents have often been associated with the privacy paradox: a paradox asserting that although adolescents consider their online privacy to be important, they do not act accordingly to protect it in specific situations (Barnes, 2006; Norberg, Horne, \& Horne, 2007). In this respect, perceived control could explain how this privacy contradiction can be altered. As shown by Xu et al. (2012), perceived control over personal information is an important intervening variable that might trigger critical privacy reflections and decisions. Thus, if specific privacy-enhancing features on a SNS can activate adolescents' perception of control, it should encourage them to actually reflect about privacy in a more pronounced way, which could then stimulate them to undertake the necessary actions or evoke critical thoughts to protect their privacy (in the context of this study, that would mean: process a targeted ad more critically). Therefore, we expect that the increase of privacy control salience will lead to an increase of perceived control among adolescents (i.e., having the feeling that they have more control over their privacy settings to manage their personal data), which in turn 
will raise their online privacy awareness and thus positively influence critical processing of targeted advertising. Hence, we propose:

H3a: The effect of increased privacy control salience (low vs. moderate; low vs. high) on critical processing will be mediated by perceived control.

At the same time, we also expect an increased privacy control salience to have a positive influence on perceived ad persuasiveness via perceived control. In a consumer behavior setting, Rose, Clark, Samouel, and Hair (2012) found that personalized marketing communications (on an online shopping website) can influence consumers' affective responses through perceived control over personal information as a mediating variable. Thus, it is key for targeted ads on SNSs to generate the perception that consumers are in control over a targeting event, which allows them to feel empowered and comfortable about the situation, which in turn should lead to positive advertising outcomes. Therefore, by increasing privacy control salience with features on Facebook's user interface, we argue that adolescents should generate higher levels of perceived control over privacy settings, which in turn will positively impact the targeted ad (i.e., an increase in perceived ad persuasiveness). Altogether, we suggest the following hypothesis:

H3b: The effect of increased privacy control salience (low vs. moderate; low vs. high) on perceived ad persuasiveness will be mediated by perceived control.

Self-efficacy. In a similar vein, self-efficacy might also be an important underlying process. Self-efficacy refers to an individual's belief or confidence in his or her ability to perform a specific task successfully within a given context (Bandura, 1977, 1997). In our specific study, it refers to a consumer's perceived ability of managing their privacy settings with regards to his or her personal information on a SNS. Several scholars have already stressed the importance of this construct in an online setting, particularly among adolescents (Hill \& Beatty, 2011; Livingstone \& Helsper, 2010). More precisely, research has found that self-efficacy is an important factor to stimulate consumers to engage in critical and responsible privacy coping behavior (Dinev \& Hart, 2005; Rifon, LaRose, \& Choi, 2005; Yao \& Linz, 2008). As argued by LaRose and Rifon (2007), consumers who believe in their ability to control private information from third parties (e.g., advertisers) should be more likely to engage in critical reflection and behavior that preserve their privacy (e.g., critical reflection on targeted advertising). Put differently, consumers' confidence in their privacy protecting abilities may make them more aware of advertisers' data collection practices, which should increase critical awareness toward these practices (i.e., a targeted ad) (Rifon et al., 2005; Youn, 2009). Therefore, we expect an increase in privacy control salience to lead to a higher consumer self-efficacy (as this privacy control salience will boost their confidence that they can exercise control over their personal information through privacy settings), which in turn should lead to more critical processing of targeted advertising. This leads to the following hypothesis:

H4a: The effect of increased privacy control salience (low vs. moderate; low vs. high) on critical processing will be mediated by self-efficacy.

In addition, Gangadharbatla (2008) argued that an increased control on SNSs may contribute to greater selfefficacy levels, which could lead to favorable responses to content on these SNSs. More precisely, he argues that the design of a SNS (and the features that are implemented on it) can help or assist users in their surfing experience and lead to higher confidence levels (i.e., self-efficacy), which in turn might lead to a positive evaluation of the content on the SNS. Following this line of reasoning, we expect that increasing privacy control, by means of features in the Facebook user interface, might lead to an increase in self-efficacy (i.e., having confidence in the ability of managing one's personal information via privacy settings), which in turn will reassure adolescents and thus lead to a better performance of the ad in terms of persuasiveness. In sum, we formulate:

H4b: The effect of increased privacy control salience (low vs. moderate; low vs. high) on perceived ad persuasiveness will be mediated by self-efficacy. 


\section{Method}

\section{Design and Participants}

Our hypotheses were tested in a single factor between-subjects design with three levels (low - moderate - high privacy control salience). The sample consisted of 178 participants aged 14-16 years old ( $M_{\text {age }}=15.34, S D=0.95$; $57 \%$ girls). Adolescents were recruited by means of a convenience sample. In May 2017, we contacted two secondary schools situated in Flanders (i.e., the Dutch speaking part of Belgium) to ask them whether they were willing to participate in the study. Both accepted this request. The principals selected several classes in the third and fourth grade of their secondary schools. The study was then conducted in the designated classrooms, during regular school time. Data collection always took place under the supervision of a teacher and one of the researchers. Formal parental consent was sought, as well as informed consent of all participants. No one refused to participate. All adolescents were informed a week in advance that they were going to participate in a study on social media (without disclosing the true purpose of the study). No reward was given for participation. Before starting the study, all adolescents were assured that their responses would be treated anonymously, and that they could withdraw their participation at any given time without negative consequences. All surveys were successfully completed.

\section{Procedure and Stimulus Material}

Participants began with filling out the survey, which started with socio-demographic questions. After having completed these questions, they were exposed to the stimulus on a new page. The stimulus material consisted of a full-sized screenshot showing a blurred Facebook profile page, with a clear sponsored post (i.e., a targeted ad) in the news feed (see Appendix). This ad promoted a fictitious sneakers brand named "Sneaky Shoe". A fictitious brand was used to avoid potential confounding effects of prior brand experiences and attitudes. The ad was created to be perceived as targeted based on personal information that we included about the adolescent's age, location and general interest in sneakers (see Zarouali, Poels, Walrave, \& Ponnet, 2018). The ad copy contained the following message: "You are X years old, you like cool sneakers, and you live in place Y? Come and visit us, and be the first with the most trendy sneakers". Every participant saw the same blurred profile page with the targeted ad, but in line with our three conditions, the screenshots did differ in their degree of privacy control salience (see next paragraph).

As argued by Hughes-Roberts (2015b), the user interface of a SNS might be an ideal context to inform and raise awareness on privacy control as it is an environment with which users interact continuously. The low privacy control salience condition displayed the newsfeed with only the 'Sneaky Shoe' targeted ad, without any privacy control element. The moderate privacy control salience condition portrayed the exact same newsfeed and ad, but this time we included a dropdown privacy control menu next to the sponsored post, allowing the user to have more control over the displayed ads (e.g., option to learn more about the targeting process, option to hide or report the ad, etc.). This menu should increase privacy control salience. Finally, the high privacy control salience condition was similar to the former one, but on top of the dropdown menu, we included an in-feed privacy notification of Facebook as well, which informs users of additional ways to secure one's personal profile (with a button to get started). For a demonstration of each experimental condition, we refer to the Appendix at the end of this manuscript. All participants were randomly assigned to one of the three conditions $\left(N_{\text {low }}=50 ; N_{\text {moderate }}=67\right.$; $N_{\text {high }}=61$ ). Of course, the inclusion of a manipulation check is essential to control whether adolescents truly perceived these screenshots as varying in their levels of privacy control salience, and thus, to test whether our low-moderate-high typology is successful (see results). After being exposed to the screenshot, participants completed the remaining part of the questionnaire, which included the dependent and independent variables, followed by the manipulation check (see measures).

\section{Measures}

As a manipulation check, we measured institutional privacy control. We employed four items based on the study of Xu, Dinev, Smith, and Hart (2008) (e.g., I believe I have control over my personal information provided to advertisers via Facebook), with response options from one (strongly disagree) to seven (strongly agree). The mean score of these 
items was used as a measure of privacy control $(M=4.60, S D=1.48 ; a=.88)$; a higher score on this measure indicates a higher privacy control salience.

Critical processing of targeted advertising was measured based on two items adapted from an existing scale of Boerman et al. (2014). This scale asked the participants to indicate to what extent (ranging from one = strongly disagree to seven = strongly agree) they agreed with two statements (e.g., "while watching the Facebook-screenshot, I criticized the message of Sneaky Shoe"). The items were aggregated to form a single measure of critical processing $(M=4.36, S D=1.31 ; a=.71)$.

To assess the perceived persuasiveness of the targeted ad, we used a three-item instrument derived from Fransen and Fennis (2014) rating the extent to which participants evaluated the advertisement to be convincing, reliable and effective. The response options ranged from one (strongly disagree) to seven (strongly agree). The mean score of the items was used as a measurement of this construct $(M=3.89, S D=1.34 ; a=.85)$.

Participants gave a score on their self-efficacy based on five items originating from the study of Meuter, Bitner, Ostrom, and Brown (2005). The items were slightly adapted to make them fit our research context. A sample item is: "I am confident in my ability to use the privacy settings for targeted ads". Respondents were given a range of response options going from one (strongly disagree) to seven (strongly agree). These items were then aggregated to form a single measurement instrument of self-efficacy $(M=4.67, S D=1.24 ; a=.84)$.

To assess perceived control, we drew upon three items used by Nysveen, Pedersen and Thorbjørnsen (2005). One of these items is: "Using the privacy settings for targeted ads is entirely within my control". The response options ranged from one (strongly disagree) to seven (strongly agree), and all items were aggregated to form a single measure of the intended construct $(M=4.64, S D=1.34 ; \alpha=.80)$. Whereas institutional privacy control, the construct used as a manipulation check (see supra), measured a general sense of control over institutional privacy on Facebook, this one is operationalized in such a way that it specifically refers to control over privacy settings on Facebook.

Finally, as a randomization check, participants were asked about their Facebook activity by using the Facebook Intensity Scale $(\alpha=.84)$, an instrument to measure the extent to which the participant actively engages in Facebook activities $(M=3.60, S D=1.35)$ (Ellison, Steinfield, \& Lampe, 2007).

\section{Results}

\section{Randomization}

The three experimental groups did not differ with respect to gender $\left(\chi^{2}(2)=0.86, p=.65\right)$ and age $\left(\chi^{2}(8)=6.07\right.$, $p=.64)$. Furthermore, results showed no significant differences in Facebook intensity between the participants of the three conditions $(F(2,175)=1.57, p=.46)$.

\section{Manipulation Check}

Overall, the three conditions differed significantly in terms of their degree of privacy control $(F(2,170)=13.72$, $p<.001)$. Bonferroni post-hoc analysis allowed us to test for pairwise comparisons. The analyses revealed that participants rated the first condition (without salient features) as being the lowest in privacy control $\left(M_{\text {low }}=3.84\right)$; then, the second condition (with the dropdown menu) was evaluated as significantly higher in terms of privacy control $\left(M_{\text {moderate }}=4.55\right.$ vs. $\left.M_{\text {low }}=3.84, p<.05\right)$; finally, the third condition (with the dropdown menu and the infeed notification) revealed the highest score for privacy control $\left(M_{\text {high }}=5.24\right.$ vs. $\left.M_{\text {moderate }}=4.55, p<.05\right)$. We therefore conclude that our low-moderate-high privacy control salience manipulation was successful.

\section{Mean Differences in Critical Processing and Perceived Ad Persuasiveness}

First, an ANOVA was conducted to test whether the privacy control salience conditions differed in terms of eliciting critical processing. Results revealed an overall significant difference among the three conditions $(F(2,175)=12.53$, 
$p<.001 ; \eta_{p}^{2}=.13$ ) (see Figure 1). Bonferroni post-hoc analysis further indicated that the moderate privacy control salience condition elicited significantly more critical processing than the low privacy control salience condition $\left(M_{\text {low }}=3.72, S D=1.48\right.$ vs $\left.M_{\text {moderate }}=4.34, S D=1.13 ; p<.05\right)$. Likewise, participants in the high privacy control salience condition scored significantly higher on critical processing as compared to those in the moderate privacy control salience condition ( $M_{\text {moderate }}=4.34, S D=1.13$ vs $\left.M_{\text {high }}=4.90, S D=1.12 ; p<.05\right)$. So, this confirms H1 stating that as privacy control salience increases from low to moderate to high, it is associated with a significant increase in critical processing of the ad among adolescents.

Second, a similar ANOVA was conducted with perceived ad persuasiveness as a dependent variable. This indicated a significant effect of the privacy control conditions on the level of perceived persuasiveness $(F(2,175)=12,49$, $p<.001 ; \eta_{p}^{2}=.13$ ) (see Figure 1). Post-hoc examination again showed significant differences between all three conditions. The moderate privacy control salience condition led to a better ad persuasiveness performance compared to the low privacy control salience condition ( $M_{\text {low }}=3.26, S D=1.22$ vs $M_{\text {moderate }}=3.85, S D=1.31 ; p<.05$ ). The high privacy control salience condition resulted in higher scores of perceived persuasiveness of targeted advertising, as compared to the moderate privacy control condition $\left(M_{\text {moderate }}=3.85, S D=1.31\right.$ vs $M_{\text {high }}=4.46$, $S D=1.24 ; p<.05)$. This confirms $\mathrm{H} 2$.

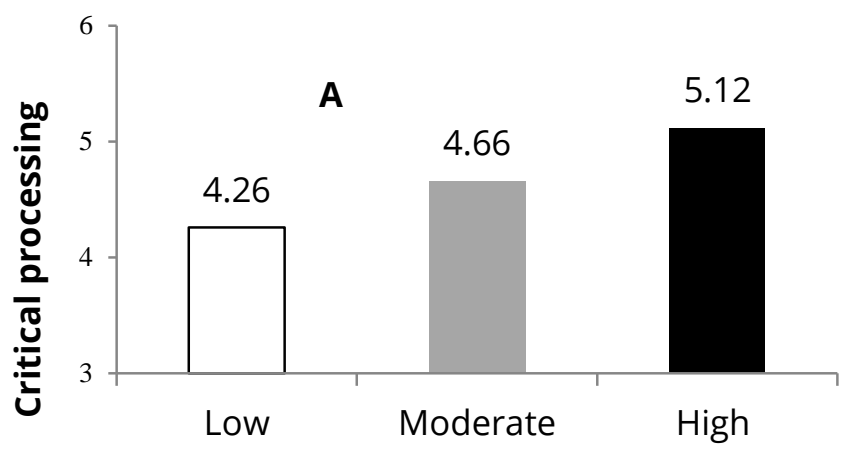

\section{Privacy Control}

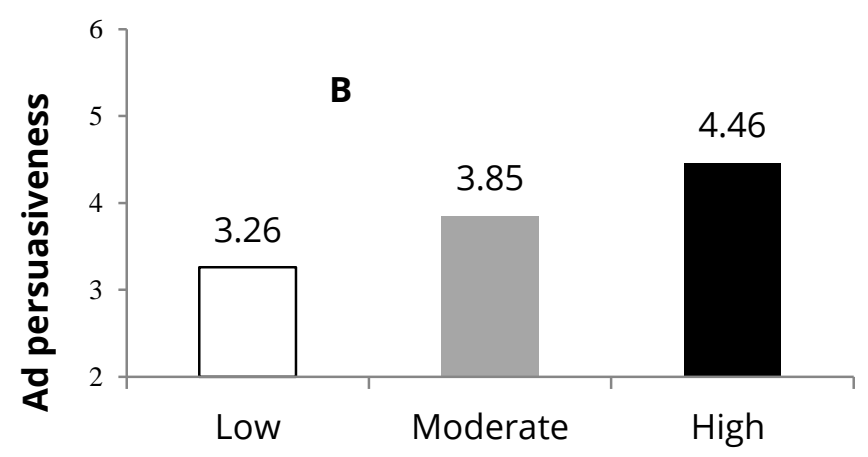

\section{Privacy Control}

Figure 1. Graphical depiction of the effect of privacy control salience on a) critical processing; b) perceived ad persuasiveness.

\section{Mediation Analyses}

Before running the mediation analyses, we analyzed the correlation between the two mediators, perceived control and self-efficacy. Pearson correlation coefficient revealed a moderate correlation with $r=.60$, meaning that there is only $36 \%$ overlap in variance $\left(r^{2}\right)$. Based on this result, we argue that the mediators are not testing the same thing, and that they are sufficiently distinct from each other. Then, we conducted the actual mediation analyses to identify whether self-efficacy and perceived control mediated the relationship between the privacy control conditions and our two outcome variables, i.e., critical processing and perceived ad persuasiveness. We used the PROCESS macro (Hayes, 2013, Model 4), and Table 1 shows the main output of our mediation analyses. Because our independent variable has three levels (low, moderate and high), we used the multicategorical option in PROCESS (see Hayes \& Preacher, 2014). In short, in case of a multicategorical independent variable with k levels, this procedure automatically generates $k-1$ dummy variables (D1, D2...Dk-1) and puts them in the mediation 
model. We chose to construct these $k-1$ dummies by using the indicator coding, which represents a coding system in which the category with the smallest numerical code or value is treated as the reference group (in this case, the 'low' privacy control salience condition has the lowest value). Altogether, this leads to two contrasts: D1 compares low with moderate privacy control salience, and D2 compares low with high privacy control salience. As a visual aid to interpret the results, we included Figure 2 in which we depict the parallel mediation model. We will now discuss the findings relating to our mediation hypotheses.

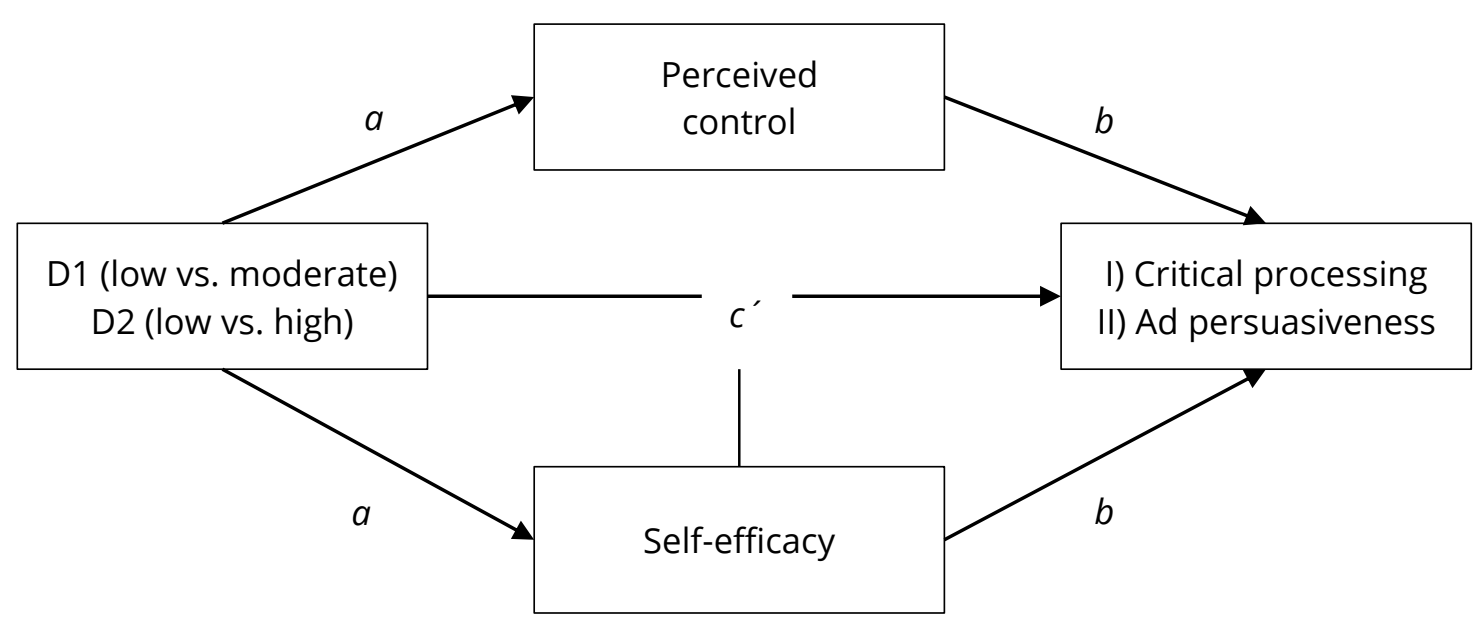

Figure 2. Statistical diagram of the hypothesized parallel mediation model.

As Table 1 illustrates, all indirect effects are statistically different from zero (no confidence interval includes the value zero). First, we can see that when privacy control is made salient (moderate and high), it indirectly (positively) influences adolescents critical processing of targeted advertising $\left(b_{\text {moderate }}=0.65 ; b_{\text {high }}=0.57\right)$, and at the same time indirectly increases perceived persuasiveness $\left(b_{\text {moderate }}=0.63 ; b_{\text {high }}=0.56\right)$ through the mediating variable perceived control as underlying psychological process. Therefore, $\mathrm{H} 3 \mathrm{a}$ and $\mathrm{H} 3 \mathrm{~b}$ are supported. Additionally, the results similarly reveal that a salient privacy control on Facebook (moderate and high) indirectly leads to adolescents being more critical about targeted advertising $\left(b_{\text {moderate }}=0.41 ; b_{\text {high }}=0.35\right)$, and at the same time indirectly boosts ad persuasiveness $\left(b_{\text {moderate }}=0.37 ; b_{\text {high }}=0.32\right.$ ), via self-efficacy as a mediator or underlying mechanism. These findings confirm H4a and H4b. Importantly, all the effects of the high privacy control condition are only partially mediated (for both mediators), as the direct effects ( $c^{\prime}$ path) are significant as well. All the other effects relating to the moderate privacy control condition are fully mediated. This will be addressed in the discussion section.

Table 1. Mediation Analyses for the Effect of Privacy Control Salience on Critical Processing and Perceived Ad Persuasiveness through Perceived Control and Self-Efficacy.

\begin{tabular}{|c|c|c|c|c|c|}
\hline \multicolumn{6}{|c|}{ Mediation Model } \\
\hline Independent variable & a path & b path & $c^{\prime}$ path & Indirect effect & $95 \% \mathrm{BC}-\mathrm{Cl}$ \\
\hline \multicolumn{6}{|c|}{ Dependent variable: critical processing; mediator: perceived control } \\
\hline D1 (low vs. moderate) & $1.35^{* * *}$ & $0.48^{* \star *}$ & -0.09 & 0.65 & 0.340 to 1.030 \\
\hline D2 (low vs. high) & $1.19^{* *}$ & $0.48^{* \star *}$ & $0.55^{*}$ & 0.57 & 0.265 to 0.964 \\
\hline \multicolumn{6}{|c|}{ Dependent variable: critical processing; mediator: self-efficacy } \\
\hline D1 (low vs. moderate) & $0.88^{* \star *}$ & $0.47^{\star \star \star}$ & 0.17 & 0.41 & 0.179 to 0.766 \\
\hline D2 (low vs. high) & $0.75^{* \star *}$ & $0.47^{* \star *}$ & $0.77^{\star * \star}$ & 0.35 & 0.120 to 0.689 \\
\hline \multicolumn{6}{|c|}{ Dependent variable: perceived ad persuasiveness; mediator: perceived control } \\
\hline D1 (low vs. moderate) & $1.35^{\star \star \star}$ & $0.46^{* \star *}$ & -0.01 & 0.63 & 0.350 to 1.021 \\
\hline D2 (low vs. moderate) & $1.19^{* *}$ & $0.46^{* * *}$ & $0.65^{\star *}$ & 0.56 & 0.294 to 0.915 \\
\hline \multicolumn{6}{|c|}{ Dependent variable: perceived ad persuasiveness; mediator: self-efficacy } \\
\hline D1 (low vs. high) & $0.88^{* \star *}$ & $0.42^{\star \star \star}$ & 0.21 & 0.37 & 0.167 to 0.683 \\
\hline D2 (low vs. high) & $0.75^{* \star *}$ & $0.42^{* \star *}$ & $0.89^{\star \star \star}$ & 0.32 & 0.117 to 0.609 \\
\hline
\end{tabular}

Note: $a$ path: relationship between the independent variable and the mediator; $b$ path: relationship between the mediator and the dependent variable; $c^{\prime}$ path: the direct effect of the independent variable on the dependent variable. D1 compares low with moderate privacy control salience; D2 compares low with high privacy control salience. $\star_{p}<.05 ; * * p<.01 ; *^{*} p<.001$. 


\section{Discussion}

Given that the user interface of a SNS is an important and strategic place with which adolescents continuously interact, the present study investigated whether and how privacy control features in the user interface could serve as a cue to influence adolescents' critical processing and responses to targeted advertisements on Facebook. The features being investigated were a privacy dropdown menu in the newsfeed and an in-feed privacy notification (see Appendix). The findings revealed that increasing privacy control salience by means of these user interface elements leads to more critical processing of targeted advertising, and at the same time, increase perceived ad persuasiveness. With regards to the underlying mechanisms explaining these effects, findings indicated that perceived control and self-efficacy served as significant mediators. On the one hand, an increase of privacy control salience on Facebook leads to the actual perception of being more in control of one's personal information via privacy settings, which leads to more scrutiny when processing targeted advertising (i.e., an increase in critical processing). In addition, the increase of privacy control salience also increases the perceived persuasiveness of a targeted ad as a result of this reassuring perceived consumer control. On the other hand, raising privacy control salience has also a positive influence on self-efficacy (i.e., having confidence in the ability of managing one's privacy settings), which then increases adolescents' critical advertising processing, and at the same time, positively influences their evaluation of the persuasiveness of targeted advertising. Theoretical contributions and practical implications will be discussed.

\section{Theoretical Contributions}

The current study contributes to theoretical advancement in three different ways. First, we offer novel insights in how young consumers can be triggered to engage in critical elaboration of persuasive messages. As already addressed in the introduction, the existing body of research mainly focused on how and when cues that convey the persuasive intent (e.g., "this is advertising") can trigger young consumers to activate their critical mindset when it comes to ads. However, this study focused on a different type of cue, namely one that conveyed perceptions of privacy control by means of user interface elements. Such cue reminds adolescents of their privacy (and the control they have over it) at the point of interaction (on the news feed), which then triggers them to engage in critical thinking about the persuasive message they encounter. The theoretical foundations underpinning these results provide new insights that have not been hitherto discussed before, offering extensions of our knowledge on how we can empower adolescents to become more critically minded with respect to targeted advertising on SNSs.

Second, this study also advances the knowledge on the effectiveness of targeted advertising. Based on the literature, we know that the element of control over the collection and use of one's personal data is important for consumers (Boerman et al., 2017). It can even be considered as one of the most important concerns regarding their online privacy (McDonald \& Cranor, 2010; Smit, Van Noort, \& Voorveld, 2014). But surprisingly, the (nature of the) relationship between privacy control and advertising evaluation is still somewhat unclear. To the best of our knowledge, this is the first study to have tested whether and how a direct increase in privacy control salience on a SNS immediately impacts the processing and evaluation of a specific targeted ad on the very same network. In testing this, we also offered a theoretical account on how increasing privacy control salience on Facebook has an indirect effect (through self-efficacy and perceived control) on ad evaluations. Based on this, we provide novel insights in the causal relationship between privacy control and ad outcomes.

Finally, we also contribute to privacy research. As asserted by Xu et al. (2012), more inquiries are needed to clarify the role of control in the information privacy literature. Recently, Williams et al. (2016) specifically called for studies that investigate the relationship between privacy control salience and consumer responses toward targeted advertising on online platforms. As a response to these calls, the present findings shed a theoretical light on the role of privacy control and two underlying mechanisms in explaining not only consumer responses, but also critical information processing among adolescents.

\section{Practical Implications}

First, our results showed that it might be beneficial for SNS providers to integrate institutional privacy control tools in the user interface and make them stand out (i.e., salient). As opposed to the general view that prompting 
consumers with tools to control privacy can be risky as it could trigger users to be cautious and skeptical, our findings indicate a different conclusion: more control and transparency about privacy and use of personal information by third parties can promote critical thinking among adolescents, while at the same time, increase advertising persuasiveness. That is, smarter consumers are not necessarily harder to persuade, implying that privacy literacy can go hand-in-hand with developed consumerism. Thus, based on current empirical findings, SNSs might consider to include and highlight privacy control features through which adolescents can protect their institutional privacy, in order to allow them to exercise meaningful control over the collection and use of personal data by the SNS provider and third parties. By incorporating greater user privacy control, SNSs will recognize adolescents' outstretched arms, which will lead to increased openness from their part to targeted ads.

For online advertisers, we offer an interesting view that increasing privacy transparency does not necessarily have to imply more vigilance and cautiousness, and hence, trigger reactance or other adverse effects. On the contrary, our findings rather indicate that disclosing opportunities to protect one's online privacy might actually pay off: young consumers seem to appreciate the fact that a brand is transparent about data collection practices, especially if they are also given the chance to do something about it through privacy settings (i.e., to control this process to a certain extent). This could indicate that privacy control salience restores their confidence and gives them the feeling that they are in control over the displayed ads.

\section{Limitations and Suggestions for Future Research}

First, it is important to acknowledge that privacy concerns about targeted advertisements depend on situational factors, including the product being promoted in the message (e.g., Acquisti, Brandimarte, \& Loewenstein, 2015; Goldfarb \& Tucker, 2012). Thus, the findings in the present study might have been influenced by our choice to use a test ad promoting a pair of shoes. One might question whether the effects would still hold in a scenario in which, for instance, health or financial products are being targeted at (young) consumers. Therefore, future research efforts might consider to install similar privacy control manipulations across different product categories.

Second, it would have been interesting to include the variables reactance and transparency in the present study. Although we have not directly measured these variables, we assume that they -at least partly- explain why privacy control salience positively influenced perceived ad persuasiveness. Privacy control salience might have yielded more ad transparency and less consumer reactance, which should then lead to more ad persuasiveness. However, it still remains necessary to test these assumptions in future research endeavors to improve our understanding on the exact role of reactance and transparency in increasing ad effectiveness as a result of privacy control salience.

Third, as already addressed in the results section, the effects of high levels of privacy control salience (i.e., the privacy dropdown menu and an in-feed privacy notification) on our dependent variable were only partially mediated, whereas for the moderate privacy control condition (i.e., only the privacy dropdown menu), full mediation occurred with some direct effects almost reaching zero. The latter is particularly intriguing because it implies that our mechanisms entirely account for the association between 'moderate' privacy control salience and our dependent variables, but not so for the 'high' condition. This leaves us to wonder which other mediators could be in play for the remaining part of the effect of high privacy control salience on our dependent variables. Therefore, this might be an interesting future research venue to obtain a better picture regarding the underlying mechanisms by which the effect of (high) privacy control salience operates.

Fourth, in our effort to increase privacy control salience, we only selected two privacy features: a privacy dropdown menu, and an in-feed privacy notification. Given that information processing and behavior can be interpreted as a continuous reaction to various environmental stimuli, it would be highly relevant to look into different privacy features that can be integrated in the user interface, and their subsequent effects. Furthermore, future studies might also focus on the placement of such privacy control initiatives: instead of only including these tools in the central newsfeed (i.e., the present study), they can also be placed in the sidebar of a network or different areas on the user interface. By doing this, we might arrive at a more accurate understanding of how SNSs should be designed in order to empower young consumers in the best possible way. 
Finally, since we merely tested our hypotheses quantitatively, the literature would highly benefit from a qualitative approach (e.g., focus groups or in-depth interviews) on the issues addressed in this study. This strategy would allow to explore the deeper and underlying meaning structures with regards to targeted ads and the role of privacy control. Scholars might delve into the private worlds and subjective viewpoints of adolescents by encouraging them to talk freely about how control over their personal information could influence their responses toward personalized ads. This can eventually lead to "hidden" thought patterns that might otherwise never be discovered with a quantitative gaze.

\section{Acknowledgements}

This work was supported by the Agentschap Innoveren en Ondernemen (Flanders Innovation \& Entrepreneurship Agency) under Grant SBO-130008. Disclosure statement: No potential conflict of interest was reported by the authors.

\section{References}

Acquisti, A., Brandimarte, L., \& Loewenstein, G. (2015). Privacy and human behavior in the age of information. Science, 347, 509-514. https://doi.org/10.1126/science.aaa1465

Aguirre, E., Roggeveen, A. L., Grewal, D., \& Wetzels, M. (2016). The personalization-privacy paradox: Implications for new media. Journal of Consumer Marketing, 33, 98-110. https://doi.org/10.1108/JCM-06-2015-1458

Ajzen, I. (2002). Perceived behavioral control, self-efficacy, locus of control, and the theory of planned behavior. Journal of Applied Social Psychology, 32, 665-683. https://doi.org/10.1111/j.1559-1816.2002.tb00236.x

Altman, I. (1975). The environment and social behavior: Privacy, personal space, territory, crowding (Clean \& Tight Contents edition). Monterey, CA: Brooks/Cde.

Armitage, C. J., \& Conner, M. (1999). Distinguishing perceptions of control from self-efficacy: Predicting consumption of a low-fat diet using the theory of planned behavior. Journal of Applied Social Psychology, 29, 7290. https://doi.org/10.1111/j.1559-1816.1999.tb01375.x

Baker, S. M., Gentry, J. W., \& Rittenburg, T. L. (2005). Building understanding of the domain of consumer vulnerability. Journal of Macromarketing, 25, 128-139. https://doi.org/10.1177/0276146705280622

Bandura, A. (1977). Self-efficacy: Toward a unifying theory of behavioral change. Psychological Review, 84, 191215. https://doi.org/10.1037/0033-295X.84.2.191

Bandura, A. (1997). Self-efficacy: The exercise of control. New York, NY: W.H. Freeman.

Barnes, S. B. (2006). A privacy paradox: Social networking in the United States. First Monday, 11(9).

https://doi.org/10.5210/fm.v11i9.1394

Bleier, A., \& Eisenbeiss, M. (2015). The Importance of trust for personalized online advertising. Journal of Retailing, 91, 390-409. https://doi.org/10.1016/j.jretai.2015.04.001

Boerman, S. C., Kruikemeier, S., \& Borgesius, F. J. Z. (2017). Online behavioral advertising: A literature review and research agenda. Journal of Advertising, 46, 363-376. https://doi.org/10.1080/00913367.2017.1339368

Boerman, S. C., \& van Reijmersdal, E. A. (2016). Informing consumers about "hidden" advertising: A literature review of the effects of disclosing sponsored content. In P. De Pelsmacker (Ed.), Advertising in new formats and media (pp. 115-146). Bingley: Emerald Group Publishing Limited.

Boerman, S. C., van Reijmersdal, E. A., \& Neijens, P. C. (2014). Effects of sponsorship disclosure timing on the processing of sponsored content: A study on the effectiveness of European disclosure regulations. Psychology \& Marketing, 31, 214-224. https://doi.org/10.1002/mar.20688

Bonneau, J., \& Preibusch, S. (2010). The privacy jungle: On the market for data protection in social networks. In T. Moore, D. Pym, \& C. Ioannidis (Eds.), Economics of information security and privacy (pp-121-167). Boston, MA: Springer. 
Brandimarte, L., Acquisti, A., \& Loewenstein, G. (2013). Misplaced confidences: Privacy and the control paradox. Social Psychological and Personality Science, 4, 340-347. https://doi.org/10.1177/1948550612455931

Brehm, J. (1989). Psychological reactance: Theory and applications. Advances in Consumer Research, 16, 72-75.

Burke, M., Marlow, C., \& Lento, T. (2009). Feed me: Motivating newcomer contribution in social network sites. In Proceedings of the SIGCHI conference on human factors in computing systems (pp. 945-954). New York, NY: ACM.

Chan, S. F., Barnes, B. R., \& Fukukawa, K. (2016). Consumer control, dependency and satisfaction with online service. Asia Pacific Journal of Marketing and Logistics, 28, 594-615. https://doi.org/10.1108/APJML-09-2015-0134

Christofides, E., Muise, A., \& Desmarais, S. (2010). Privacy and disclosure on Facebook: Youth and adults' information disclosure and perceptions of privacy risks. Guelph: University of Guelph.

Debatin, B., Lovejoy, J. P., Horn, A.-K., \& Hughes, B. N. (2009). Facebook and online privacy: Attitudes, behaviors, and unintended consequences. Journal of Computer-Mediated Communication, 15, 83-108.

https://doi.org/10.1111/j.1083-6101.2009.01494.x

Dinev, T., \& Hart, P. (2005). Internet privacy concerns and social awareness as determinants of intention to transact. International Journal of Electronic Commerce, 10(2), 7-29. https://doi.org/10.2753/JEC1086-4415100201

Eagly, A. H., Wood, W., \& Chaiken, S. (1978). Causal inferences about communicators and their effect on opinion change. Journal of Personality and Social Psychology, 36, 424. https://doi.org/10.1037/0022-3514.36.4.424

Einstein, M. (2016). Black ops advertising: Native ads, content marketing and the covert world of the digital sell. London: OR Books.

Ellison, N. B., Steinfield, C., \& Lampe, C. (2007). The benefits of Facebook "friends:" Social capital and college students' use of online social network sites. Journal of Computer-Mediated Communication, 12, 1143-1168. https://doi.org/10.1111/j.1083-6101.2007.00367.x

Fransen, M. L., \& Fennis, B. M. (2014). Comparing the impact of explicit and implicit resistance induction strategies on message persuasiveness. Journal of Communication, 64, 915-934.

https://doi.org/10.1111/jcom.12118

Gangadharbatla, H. (2008). Facebook me: Collective self-esteem, need to belong, and internet self-efficacy as predictors of the igeneration's attitudes toward social networking sites. Journal of Interactive Advertising, 8, 5-15. https://doi.org/10.1080/15252019.2008.10722138

Goldfarb, A., \& Tucker, C. (2011). Online display advertising: Targeting and obtrusiveness. Marketing Science, 30, 389-404. https://doi.org/10.1287/mksc.1100.0583

Goldfarb, A., \& Tucker, C. (2012). Shifts in privacy concerns. American Economic Review, 102, 349-353. https://doi.org/10.1257/aer.102.3.349

Hawk, S. T., Hale, W. W., Raaijmakers, Q. A. W., \& Meeus, W. (2008). Adolescents' perceptions of privacy invasion in reaction to parental solicitation and control. The Journal of Early Adolescence, 28, 583-608.

https://doi.org/10.1177/0272431608317611

Hayes, A. F. (2013). Introduction to mediation, moderation, and conditional process analysis: A regression-based approach. New York, NY: The Guilford Press.

Hayes, A. F., \& Preacher, K. J. (2014). Statistical mediation analysis with a multicategorical independent variable. British Journal of Mathematical and Statistical Psychology, 67, 451-470. https://doi.org/10.1111/bmsp.12028

Hill, W. W., \& Beatty, S. E. (2011). A model of adolescents' online consumer self-efficacy (OCSE). Journal of Business Research, 64, 1025-1033. https://doi.org/10.1016/j.jbusres.2010.11.008

Houghton, D. J., \& Joinson, A. N. (2010). Privacy, social network sites, and social relations. Journal of Technology in Human Services, 28, 74-94. https://doi.org/10.1080/15228831003770775

Hudders, L., Pauw, P. D., Cauberghe, V., Panic, K., Zarouali, B., \& Rozendaal, E. (2017). Shedding new light on how advertising literacy can affect children's processing of embedded advertising formats: A future research agenda. Journal of Advertising, 0, 1-17. https://doi.org/10.1080/00913367.2016.1269303 
Hughes-Roberts, T. (2015a). Privacy as a secondary goal problem: An experiment examining control. Information and Computer Security, 23, 382-393. https://doi.org/10.1108/ICS-10-2014-0068

Hughes-Roberts, T. (2015b). Reminding users of their privacy at the point of interaction: The effect of privacy salience on disclosure behaviour. In T. Tryfonas \& I. Askoxylakis (Eds.), Human aspects of information security, privacy, and trust (pp. 347-356). Cham: Springer.

Koufaris, M., Kambil, A., \& Labarbera, P. A. (2001). Consumer behavior in web-based commerce: An empirical study. International Journal of Electronic Commerce, 6(2), 115-138.

https://doi.org/10.1080/10864415.2001.11044233

LaRose, R., \& Rifon, N. J. (2007). Promoting i-safety: Effects of privacy warnings and privacy seals on risk assessment and online privacy behavior. Journal of Consumer Affairs, 41, 127-149. https://doi.org/10.1111/j.17456606.2006.00071.x

Lawlor, M.-A., Dunne, Á., \& Rowley, J. (2016). Young consumers' brand communications literacy in a social networking site context. European Journal of Marketing, 50, 2018-2040. https://doi.org/10.1108/EJM-06-2015-0395

Livingstone, S. (2006). Children's privacy online: Experimenting with boundaries within and beyond the family. In R. E. Kraut, M. Brynin, \& S. Kiesler (Eds.), Computers, phones, and the Internet: Domesticating information technology. Oxford; New York, NY: Oxford University Press.

Livingstone, S. (2008). Taking risky opportunities in youthful content creation: Teenagers' use of social networking sites for intimacy, privacy and self-expression. New Media \& Society, 10, 393-411.

Livingstone, S., \& Helsper, E. (2010). Balancing opportunities and risks in teenagers' use of the internet: The role of online skills and internet self-efficacy. New Media \& Society, 12, 309-329.

Margulis, S. T. (1977). Conceptions of privacy: Current status and next steps. Journal of Social Issues, 33(3), 5-21. https://doi.org/10.1111/j.1540-4560.1977.tb01879.x

Margulis, S. T. (2003). Privacy as a social issue and behavioral concept. Journal of Social Issues, 59, 243-261. https://doi.org/10.1111/1540-4560.00063

McDonald, A. M., \& Cranor, L. F. (2010). Americans' attitudes about internet behavioral advertising practices. In Proceedings of the 9th Annual ACM Workshop on Privacy in the Electronic Society (pp. 63-72). New York, NY: ACM.

Meuter, M. L., Bitner, M. J., Ostrom, A. L., \& Brown, S. W. (2005). Choosing among alternative service delivery modes: An investigation of customer trial of self-service technologies. Journal of Marketing, 69(2), 61-83. https://doi.org/10.1509/jmkg.69.2.61.60759

Morris, J. D., Choi, Y., \& Ju, I. (2016). Are social marketing and advertising communications (SMACs) meaningful?: A survey of Facebook user emotional responses, source credibility, personal relevance, and perceived intrusiveness. Journal of Current Issues \& Research in Advertising, 37, 165-182.

https://doi.org/10.1080/10641734.2016.1171182

Norberg, P. A., Horne, D. R., \& Horne, D. A. (2007). The privacy paradox: Personal information disclosure intentions versus behaviors. Journal of Consumer Affairs, 41, 100-126. https://doi.org/10.1111/j.17456606.2006.00070.x

Nysveen, H., Pedersen, P. E., \& Thorbjørnsen, H. (2005). Intentions to use mobile services: Antecedents and cross-service comparisons. Journal of the Academy of Marketing Science, 33, 330-346.

https://doi.org/10.1177/0092070305276149

Ofcom. (2017). Children and Parents: Media Use and Attitudes Report. Retrieved from https://www.ofcom.org.uk/research-and-data/media-literacy-research/childrens/children-parents-2017

PEW Research Center. (2018). Teens, Social Media \& Technology 2018 (pp. 1-19).

Quinn, J. M., \& Wood, W. (2004). Forewarnings of influence appeals: Inducing resistance and acceptance. In E. S. Knowles \& J. A. Linn (Eds.), Resistance and persuasion (pp. 193-213). Mahwah, N.J: Lawrence Erlbaum Associates. 
Raines, A. M., Oglesby, M. E., Unruh, A. S., Capron, D. W., \& Schmidt, N. B. (2014). Perceived control: A general psychological vulnerability factor for hoarding. Personality and Individual Differences, 56, 175-179.

https://doi.org/10.1016/j.paid.2013.09.005

Raynes-Goldie, K. (2010). Aliases, creeping, and wall cleaning: Understanding privacy in the age of Facebook. First Monday, 15(1). Rifon, N. J., LaRose, R., \& Choi, S. M. (2005). Your privacy is sealed: Effects of web privacy seals on trust and personal disclosures. Journal of Consumer Affairs, 39, 339-362. https://doi.org/10.1111/j.1745-

6606.2005.00018.x

Rose, S., Clark, M., Samouel, P., \& Hair, N. (2012). Online customer experience in e-retailing: An empirical model of antecedents and outcomes. Journal of Retailing, 88, 308-322. https://doi.org/10.1016/j.jretai.2012.03.001

Rosenblatt, S. (2014). Facebook's privacy checkup helps you figure out who's seeing what. CNET. Retrieved from https://www.cnet.com/news/facebook-launches-its-privacy-checkup/

Shimp, T. A., \& Andrews, J. C. (2013). Advertising, promotion, and other aspects of integrated marketing communications (9th ed). Mason, OH: South-Western Cengage Learning.

Smit, E. G., Van Noort, G., \& Voorveld, H. A. M. (2014). Understanding online behavioural advertising: User knowledge, privacy concerns and online coping behaviour in Europe. Computers in Human Behavior, 32, 15-22. https://doi.org/10.1016/j.chb.2013.11.008

Smith, H. J., Milberg, S. J., \& Burke, S. J. (1996). Information privacy: Measuring individuals' concerns about organizational practices. MIS Quarterly, 20, 167-196. https://doi.org/10.2307/249477

Solove, D. J. (2002). Conceptualizing privacy. California Law Review, 90, 1087-1155.

https://doi.org/10.2307/3481326

Solove, D. J. (2005). A Taxonomy of privacy. University of Pennsylvania Law Review, 154, 477-564.

https://doi.org/10.2307/40041279

Stutzman, F., Gross, R., \& Acquisti, A. (2013). Silent listeners: The evolution of privacy and disclosure on Facebook. Journal of Privacy and Confidentiality, 4, 7-41. https://doi.org/10.29012/jpc.v4i2.620

Taylor, S. E. (1979). Hospital patient behavior: Reactance, helplessness, or control? Journal of Social Issues, 35(1), 156-184. https://doi.org/10.1111/j.1540-4560.1979.tb00793.x

Trepte, S., \& Reinecke, L. (Eds.). (2011). Privacy online. Berlin: Springer.Tucker, C. E. (2014). Social networks, personalized advertising, and privacy controls. Journal of Marketing Research, 51, 546-562.

https://doi.org/10.1509/jmr.10.0355

Van Reijmersdal, E. A., Rozendaal, E., Smink, N., Noort, G. van, \& Buijzen, M. (2017). Processes and effects of targeted online advertising among children. International Journal of Advertising, 36, 396-414.

https://doi.org/10.1080/02650487.2016.1196904

Vitak, J. (2015). Balancing privacy concerns and impression management strategies on Facebook. In Symposium on Usable Privacy and Security (SOUPS).

Walrave, M., Poels, K., Antheunis, M. L., Van den Broeck, E., \& Noort, G. van. (2016). Like or dislike? Adolescents' responses to personalized social network site advertising. Journal of Marketing Communications. Advance online publication. https://doi.org/10.1080/13527266.2016.1182938

Wang, N., Xu, H., \& Grossklags, J. (2011). Third-party apps on Facebook: Privacy and the illusion of control. In Proceedings of the 5th ACM symposium on computer human interaction for management of information technology. New York, NY: ACM.

Wang, N., Zhang, B., Liu, B., \& Jin, H. (2015). Investigating effects of control and ads awareness on Android users' privacy behaviors and perceptions. In Proceedings of the 17th international conference on human-computer interaction with mobile devices and services (pp. 373-382). New York, NY: ACM.

Wei, M.-L., Fischer, E., \& Main, K. J. (2008). An examination of the effects of activating persuasion knowledge on consumer response to brands engaging in covert marketing. Journal of Public Policy \& Marketing, 27(1), 34-44.

https://doi.org/10.1509/jppm.27.1.34 
Westin, A. F. (1967). Privacy and freedom. New York, NY: Atheneum.

Williams, M., Nurse, J. R., \& Creese, S. (2016). Privacy salience: Taxonomies and research opportunities. In A. Lehmann, D. Whitehouse, S. Fischer-Hübner, L. Fritsch, \& C. Raab (Eds.), Privacy and identity management. Facing up to next steps (pp. 263-278). Cham: Springer.

Wojdynski, B. W. (2016). Native advertising: Engagement, deception, and implications for theory. In R. E. Brown, V. K. Jones, \& M. Wang (Eds.), The new advertising: Branding, content and consumer relationships in a data-driven social media era (pp. 203-236). Santa Barbara, CA: Praeger/ABC Clio.

Wolfe, M., \& Laufer, R. S. (1974). The concept of privacy in childhood and adolescence. In S. T. Margulis (Ed.), Privacy (pp. 29-54). Stony Brook, NY: Environmental Design Research.

$\mathrm{Xu}, \mathrm{H}$. (2007). The effects of self-construal and perceived control on privacy concerns. In Proceedings of the 28th International Conference on Information Systems. Montreal, Canada.

Xu, H., Dinev, T., Smith, H. J., \& Hart, P. (2008). Examining the formation of individual's privacy concerns: Toward an integrative view. ICIS 2008 Proceedings, paper 6.

Xu, H., Teo, H.-H., Tan, B. C. Y., \& Agarwal, R. (2012). Research note - effects of individual self-protection, industry self-regulation, and government regulation on privacy concerns: A study of location-based services. Information Systems Research, 23, 1342-1363. https://doi.org/10.1287/isre.1120.0416

Yao, M. Z., \& Linz, D. G. (2008). Predicting self-protections of online privacy. CyberPsychology \& Behavior, 11, 615617. https://doi.org/10.1089/cpb.2007.0208

Youn, S. (2009). Determinants of online privacy concern and its influence on privacy protection behaviors among young adolescents. Journal of Consumer Affairs, 43, 389-418. https://doi.org/10.1111/j.1745-6606.2009.01146.x

Young, A. L., \& Quan-Haase, A. (2013). Privacy protection strategies on Facebook. Information, Communication \& Society, 16, 479-500. https://doi.org/10.1080/1369118X.2013.777757

Zarouali, B., Poels, K., Walrave, M., \& Ponnet, K. (2018). The impact of regulatory focus on adolescents' evaluation of targeted advertising on social networking sites. International Journal of Advertising. Advance online publication. https://doi.org/10.1080/02650487.2017.1419416

Zarouali, B., Ponnet, K., Walrave, M., \& Poels, K. (2017). "Do you like cookies?" Adolescents' skeptical processing of retargeted Facebook-ads and the moderating role of privacy concern and a textual debriefing. Computers in Human Behavior, 69, 157-165. https://doi.org/10.1016/j.chb.2016.11.050

\section{Correspondence to:}

Brahim Zarouali

Department of Communication Studies, University of Antwerp

Sint-Jacobsstraat 2

2000 Antwerp

Belgium

E-mail: brahim.zarouali(at)uantwerp.be

Tel: +32 32655049

Editorial record: First submission received on January 25, 2018. Revision received on May 13, 2018. Accepted for publication on July 2, 2018. 


\section{Appendix}

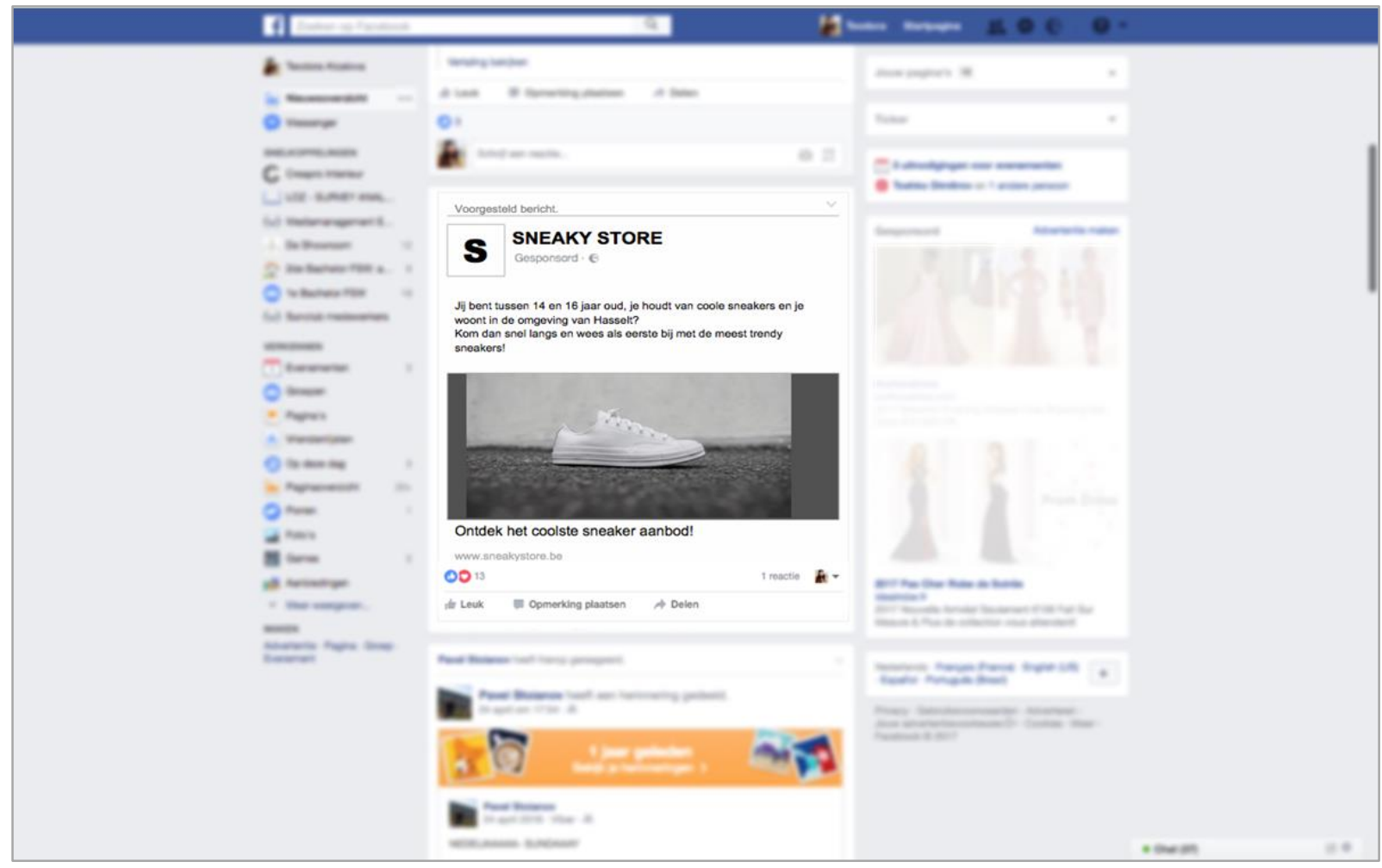

Figure A1. Low privacy control salience condition (without privacy feature).

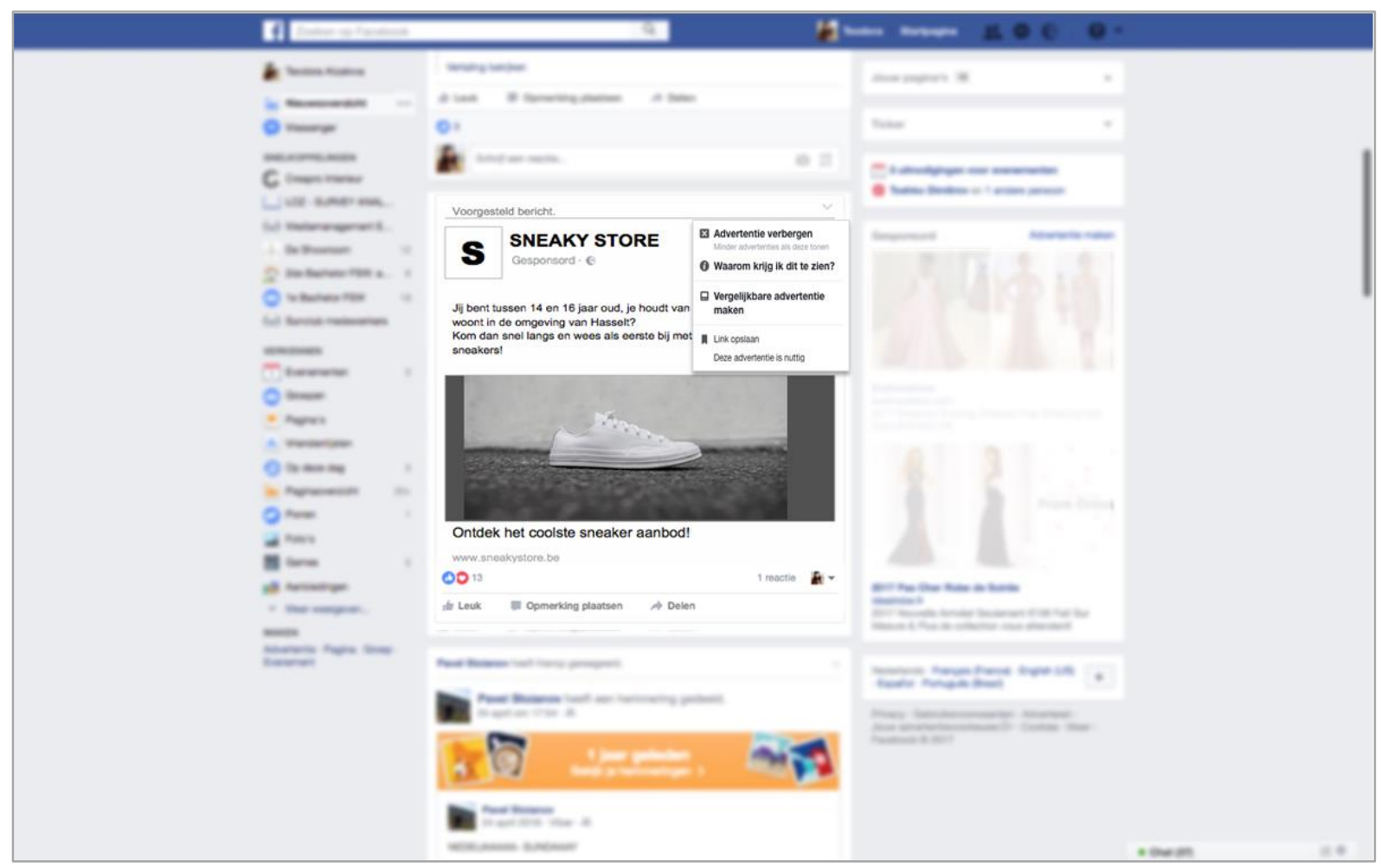

Figure A2. Moderate privacy control salience condition (with privacy dropdown menu). 


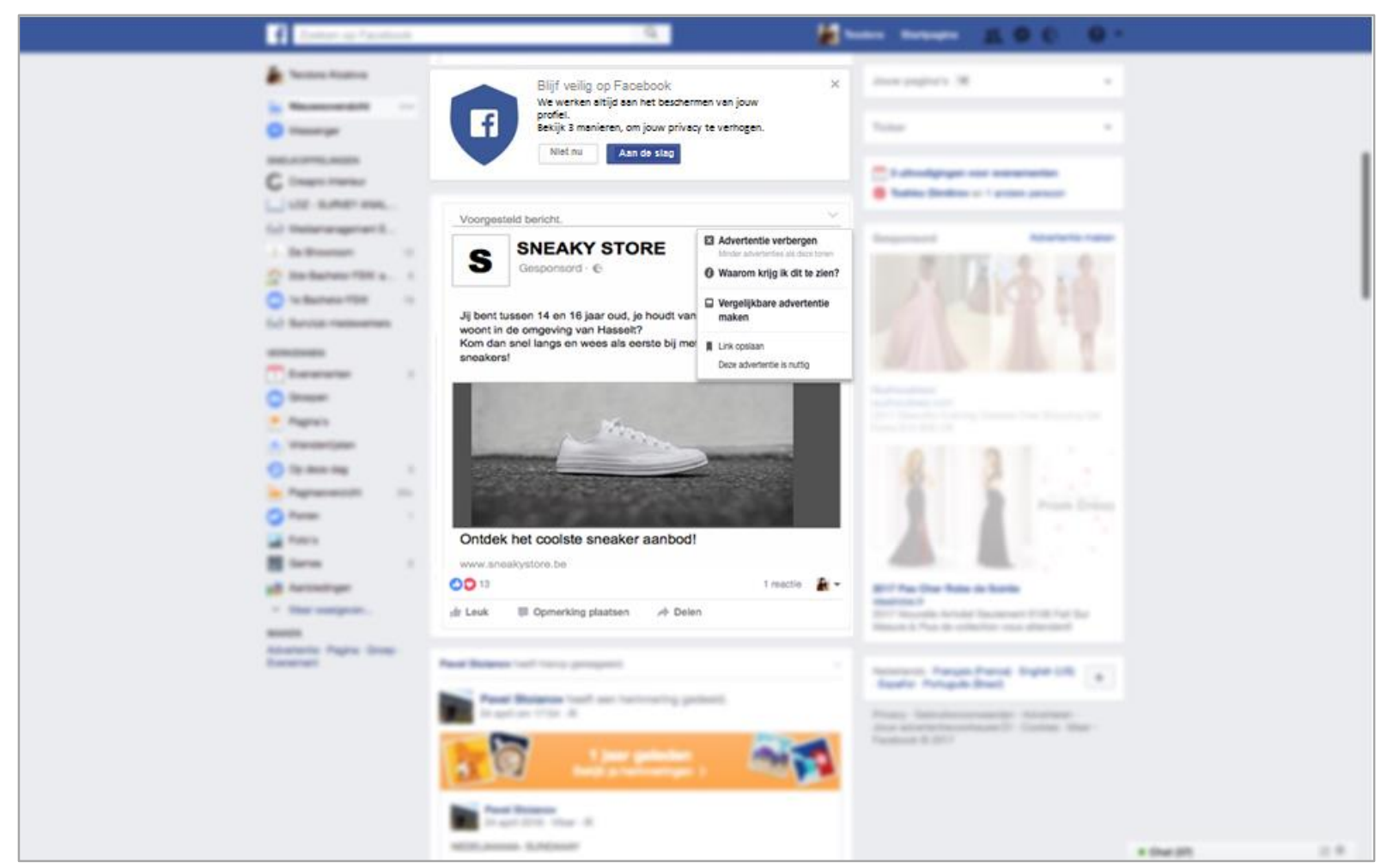

Figure A3. High privacy control salience condition (with privacy dropdown menu and in-feed privacy notification). 


\section{About Authors}

Brahim Zarouali is a PhD candidate at the department of Communication Studies of the University of Antwerp, Belgium. He obtained his master's degree in Strategic Communication with great distinction. His fields of interest are advertising persuasion, consumer psychology and online privacy across various information and communication technologies (e.g., the web, social media, mobile environments, digital television, etc.). More precisely, his doctoral research focuses on how adolescents process and respond to personalized advertising on social networking sites, and how this vulnerable group of consumers can be protected and empowered. This research is part of the AdLit-project (http://www.adlit.be), an interdisciplinary project on advertising literacy among children and adolescents.

Karolien Poels is a professor of Strategic Communication and Persuasive Technology at the Department of Communication Studies, University of Antwerp, Belgium. She is a member of the research group MIOS (Media \& ICT in Organizations \& Society). Starting in the field of advertising, digital games and emotions, Karolien's research has (co-) developed in other ICT areas, mainly social media. In her research she focuses on how individuals use and experience ICT and how these insights can be applied in the broad field of persuasive communication. This has led to numerous projects and publications on topics such as advertising processing and effectiveness, digital gaming experience and effects, health promotion and prevention of online anti-social behavior, crisis communication in an age of social media, consumer protection and empowerment in online environments, often with minors as a vulnerable group. Within most of her studies, affective reactions (feelings, emotions) play a major role. Karolien is vice-president of NeFCA (Netherlands-Flanders Communication Association), and co-chair of the Persuasive Communication division from NeFCA.

Koen Ponnet works at the Faculty of Social Sciences, Ghent University, and conducts research in Health Psychology, Media Psychology and Social Psychology. He examines the determinants of online and offline health and risk behaviors of adolescents and adults (e.g., sexting, online self-disclosure, depressive symptoms, drug use, unsafe and unsecure behavior, attitudinal changes). Koen Ponnet deliberately conducts research that has implications for theory-building as well as relevance for practice and policy.

Michel Walrave is a professor at the Department of Communication Studies of the University of Antwerp. He is responsible for the research group MIOS. His research is centered around online self-disclosure and privacy. He investigates individuals' self-disclosure and privacy in interpersonal online communication on social network sites. More particularly, his research focuses on self-disclosure's opportunities (e.g., social capital) as well as risks (e.g., cyberbullying). He also investigates sensitive disclosures (e.g., sexting), their motives and consequences. Next to interpersonal self-disclosures, he also studies internet users' entrusting of personal data to businesses and how consumers deal with new forms of interactive marketing. 